\title{
Reducing gasoline loss from evaporation by the introduction of a surface-active fuel additive
}

\author{
E. Magaril \\ Ural Federal University, Russia
}

\begin{abstract}
Apart from the emission of hydrocarbons within the exhaust gases of vehicles, gasoline hydrocarbons are released into the environment from the tanks of cars during refueling and also during transportation and storage as a result of evaporation. Losses of gasoline when moving from producer to consumer are $1.5-2 \%$. Up to $40 \%$ of the hydrocarbons emitted by road transport evaporate from the fuel systems of cars with gasoline engines. In the context of the global problem of depleting energy resources and the associated degradation of the environment the reduction of gasoline losses from evaporation remains an important environmental and economic issue. The aim of this work is to validate a method of reducing evaporation loss by modifying the quality of the fuel being used. An approach to assessing the toxicity of gasoline vapor has been proposed which may point to the effect that the individual components of gasoline have on this. A method has been developed to reduce evaporation loss and also improve the mixture in the engine by introducing a fuel additive which is a surface-active agent. The additive reduces the vapor pressure of gasoline while also reducing the surface tension of the fuel droplets at the interface with air. The results from studies on the additive's effect on the saturated vapor pressure, surface tension, and gasoline evaporation losses are given.

Keywords: evaporation losses, relative toxicity index, saturated vapor pressure, surface-active agent, gasoline additive.
\end{abstract}

\section{Introduction}

Evaporation losses of oil and gasoline from tanks and other containers cannot be completely eliminated under the current level of technology used in the transportation and storage of hydrocarbons. This is the cause of both economic 
loss to the gasoline station owners and environmental damage from air pollution. In metropolitan areas the negative consequences of gasoline loss through evaporation are exacerbated by the high building density, the concentration of vehicles, the ever increasing transport volume [1] and turnaround at the gasoline station tanks. Also the loss of gasoline from evaporation leads to a deterioration in its quality and increases the specific consumption when a vehicle is operating due to the changes in its physicochemical characteristics:

Reducing the loss of gasoline through evaporation is a critical factor in the rational use of fuel and energy resources and minimising the environmental impact.

Basically, losses through evaporation include losses from saturation of the gas space of new or reconstructed gasoline station tanks with vapor-air mixture; losses caused by the displacement of vapor-air mixture saturated with gasoline vapor from the tank during its filling and pumping; losses caused by daily fluctuations in temperature and atmospheric pressure and partial pressure of gasoline vapor in the gas space of the tank. Different technical solutions may be used to reduce gasoline loss through evaporation, in particular, specially designed tanks and systems that capture light hydrocarbons. But the disadvantages of such systems are their complexity, the necessary capital expenditure and their explosiveness. The same time evaporation loss may be reduced by influencing the properties of the gasoline being used. The topical aim is to validate a low-cost, quickly implemented method of reducing evaporation loss of gasoline by modifying its quality.

\section{Evaluation of toxicity of gasoline vapor}

Toxicity of gasoline vapor is defined by the vapor pressure and toxicity of components of gasoline vapor.

Concentration of the substances in the vapor in equilibrium with the liquid for ideal mixtures can be determined by combining Raoult's law with Dalton's law as $y=\frac{P}{\pi} x$, where $\mathrm{y}$ is the mole fraction of the component in the vapor, $\mathrm{x}$ is the mole fraction in the liquid, $\mathrm{P}$ - saturated vapor pressure of the component at a given temperature, $\pi$ - the total vapor pressure.

Different components of gasoline vary widely in toxicity and can be measured using the value of the maximum allowable concentration $(M A C)$.

If the concentration of the component in the vapor is $\mathrm{Ci}$, the toxicity caused by this component can be measured by the value of $C_{i} / M A C_{i}$, and the total toxicity of gasoline vapor is $\Sigma C_{i} / M A C_{i}$.

Let in gasoline with an average molecular weight $M_{l}$ there is $x$ wt.\% of component with molecular weight $M_{2}$ and its vapor pressure at a given temperature $T$ is $P, \mathrm{kPa}$. Then the saturated vapor concentration of this component above the gasoline will be equal to:

$$
C=\frac{x / M_{2}}{x / M_{2}+(100-x) / M_{1}} \cdot \frac{P}{101.3} \cdot \frac{M_{2} \cdot 273}{22.4 \cdot T} \cdot 10^{6} \mathrm{mg} / \mathrm{m}^{3}
$$


At $x=1$ and $M_{l}=100$ :

$$
C=\frac{P}{1 / M_{2}+0.99} \cdot \frac{273}{101.3 \cdot 22.4 \cdot T} \cdot 10^{6}
$$

At $30^{\circ} \mathrm{C} \mathrm{C} \approx 397 P \mathrm{mg} / \mathrm{m}^{3}$ or in $M A C$ units, $397 \frac{P}{M A C}$.

It is more convenient to characterize the vapor toxicity of the various components of gasoline by using a $P / M A C$ value which is independent of temperature and can serve as a conventional measure of relative toxicity (CMRT). Table 1 shows the values of CMRT obtained using the values of daily average $M A C$, established in Russia.

Table 1: Conventional measure of relative toxicity of the gasoline components in the air of a populated area.

\begin{tabular}{|c|c|c|}
\hline Gasoline component & CMRT & $\frac{C M R T}{C M R T_{C_{5} H_{12}}}$ \\
\hline${\mathrm{n}-\mathrm{C}_{5} \mathrm{H}_{12}}$ & 3.3 & 1.0 \\
\hline $\mathrm{C}_{5} \mathrm{H}_{10}$ (pentene, mixture) & 56.5 & 17.1 \\
\hline $\mathrm{n}-\mathrm{C}_{6} \mathrm{H}_{12}-1$ & 359.5 & 108.9 \\
\hline $\mathrm{n}-\mathrm{C}_{7} \mathrm{H}_{14}-1$ & 15.4 & 4.7 \\
\hline $\mathrm{C}_{6} \mathrm{H}_{6}$ & 159.1 & 48.2 \\
\hline $\mathrm{C}_{7} \mathrm{H}_{8}$ & 8.2 & 2.5 \\
\hline $\mathrm{C}_{6} \mathrm{H}_{5} \mathrm{CH}\left(\mathrm{CH}_{3}\right)_{2}$ & 29.0 & 8.8 \\
\hline $\mathrm{CH}_{3} \mathrm{OC}\left(\mathrm{CH}_{3}\right)_{3}$ & 423.3 & 128.3 \\
\hline
\end{tabular}

Concurring with data presented in Table 1, the most toxic component of the gasoline is methyl tert-butyl ether (MTBE) which is determined by the high value of its vapor pressure and the low value of daily average $M A C$ in the air of a populated area $\left(0.1 \mathrm{mg} / \mathrm{m}^{3}\right)$. Table 1 shows that the maximum gasoline vapor toxicity at the same concentration is associated with MTBE, benzene and 1-nhexene. MACs and, accordingly, CMRT ignores the "lifetime" of the hydrocarbon in air. 1-n-hexene is relatively quickly oxidized by the oxygen in the air and is removed from the atmosphere. Benzene is practically not subject to any chemical reactions under normal conditions, is not subjected to the action of microorganisms and the duration of its unchanged existence is not defined.

It is necessary to take into account that $M A C$ of MTBE in the air of populated area seems to be exaggerated due to its pungent odor. However, the solubility of MTBE in water $(4.8 \%)$ and leakage of bottom water from the gasoline tanks with subsequent release of MTBE into the water supply system led to the prohibition of the use of gasoline containing MTBE in the USA since 2010 (in the state of California since 2003).

Table 2 shows the calculated vapor toxicity of the n-hexane binary mixtures containing $5 \mathrm{wt} . \%$ of a second component at $30^{\circ} \mathrm{C}$ and $101.3 \mathrm{kPa}$. The average daily maximum allowable concentration in the air of populated area for $n$-hexane is taken to be $15 \mathrm{mg} / \mathrm{m}^{3}$. 
Table 2: Toxicity of the $\mathrm{n}$-hexane and its mixture vapors with the second component concentration equal to $5 \mathrm{wt} . \%\left(101.3 \mathrm{kPa}, 30^{\circ} \mathrm{C}\right)$.

\begin{tabular}{|c|c|c|c|c|}
\hline \multirow[b]{2}{*}{ Component } & \multirow[b]{2}{*}{$\begin{array}{c}\text { Vapor } \\
\text { pressure, } \\
\mathrm{kPa}\end{array}$} & \multirow{2}{*}{$\begin{array}{c}\text { Component } \\
\text { concentration in } \\
\text { vapor, } \mathrm{mg} / \mathrm{m}^{3}\end{array}$} & \multicolumn{2}{|c|}{ Vapor toxicity } \\
\hline & & & $\begin{array}{l}\text { in } \\
\text { MAC } \\
\text { units }\end{array}$ & $\begin{array}{l}\text { related to } \\
\text { hexane }\end{array}$ \\
\hline- & 25.43 & 963800 & 64240 & 1.00 \\
\hline 1-n-Hexene & 30.96 & 58450 & 748610 & 11.65 \\
\hline 1-n-Heptene & 9.64 & 18320 & 343260 & 5.34 \\
\hline Benzene & 15.91 & 30080 & 361510 & 5.63 \\
\hline Toluene & 4.89 & 9300 & 76730 & 1.19 \\
\hline Ethyl benzene & 1.57 & 3010 & 212710 & 3.31 \\
\hline Isopropyl benzene & 0.40 & 760 & 116210 & 1.81 \\
\hline
\end{tabular}

The data in Table 2 shows that with an equal weight content 1-hexene and benzene give the greatest increase in toxicity of vapors and the aromatic hydrocarbons $\mathrm{C}_{7+}$ increase the toxicity of gasoline vapor to a lesser extent than benzene. Benzene contributes to the toxicity of vapors of gasoline significantly more than other aromatic hydrocarbons at the equal content due to the high vapor pressure.

It worth noting that the current average $M A C$ in the air of a populated area for gasoline $\left(1.5 \mathrm{mg} \mathrm{C} / \mathrm{m}^{3}\right)$ does not consider the chemical composition of gasoline. To meet the $M A C$ standards for gasoline the benzene concentration in the gasoline vapor should not exceed $5.7 \%$. Since benzene has a significantly higher vapor pressure than gasoline in general, the benzene content in gasoline must be much lower to meet the $M A C$ standards for benzene.

Our data show that a significant proportion of the total toxicity of gasoline vapor in Russia is caused by benzene [2] which is chemically stable under normal conditions and does not undergo biodegradation.

Considering the short "lifetime" of hexene and MTBE and the chemical stability of benzene, the most toxic component of gasoline is benzene. However, the undesirability of MTBE and $\mathrm{C}_{6} \mathrm{H}_{12}$ alkenes in the gasoline content must also be taken into account.

In view of the fact that increased concentrations of benzene in gasoline also cause elevated carbon deposit formation, adversely affecting the environmental and operational performance of vehicles [3-5], it is necessary to limit its content, as required by the standards of the Worldwide Fuel Charter (less than 1\%) [6]. In this regard one of the strategic objectives of the refining industry is to build up the capacity of the isomerization while limiting reforming of the raw materials boiling below $100^{\circ} \mathrm{C}[2]$. 


\section{Reducing gasoline loss from evaporation using surface-active substances}

\subsection{Substantiation of the method to reduce gasoline loss from evaporation}

Reducing gasoline losses to evaporation during storage, the refueling process and from the tanks of cars by improving the relevant equipment requires significant capital expenditure. Efforts to reduce gasoline loss through evaporation led to the restriction in saturated vapor pressure value; in the summer season at the temperatures above $+15^{\circ} \mathrm{C}$ is about $45-60 \mathrm{kPa}$.

Fundamentally, reducing gasoline vapor pressure without changing its composition may be achieved by introducing a fuel additive that is a surfaceactive substance. Concentration of the additive in the surface layer of the gasoline reduces the concentration of hydrocarbons therein. Vapor pressure can be written as $P=\sum P_{i} x_{i}$, where $P_{i}$ is the saturated vapor pressure of the hydrocarbon in its pure form and $x_{i}$ is its mole fraction on the surface of the gasoline. The presence of the involatile additive in the surface layer reduces $x_{i}$ so that it, in turn, reduces the saturated vapor pressure according to Raoult-Dalton's law.

This lowering of the saturated vapor pressure may complicate cold starts. However, the rate of evaporation of fuel droplets at the air temperature below the boiling point is proportional to $P \cdot S$, where $S$ is the surface of the fuel droplets. The surface of the droplets is related to the surface tension of gasoline $\sigma$ on the boundary with air by $S \sim 1 / \sigma$ relation as specified by the author.

For a given density of gasoline the diameter of fuel droplets $\mathrm{d}$ is proportional to the surface tension $\sigma$ and the total droplet surface $S$ is inversely proportional to the surface tension [7-9]. Introducing into the gasoline the surface-active substance that reduces the surface tension of gasoline decrease in droplet diameter; the surface of the drops increases and, as was stated by the author, the evaporation rate increases in an inverse proportion to the square of the surface tension.

Thus, the introduction of surface-active substances into the gasoline reduces the vapor pressure which reduces the loss from evaporation while improving the mixture within the engine.

\subsection{Results of the application of the surface-active fuel additive}

A highly efficient gasoline additive based on a derivative of synthetic fatty acids with significant surfactant activity was developed by the author [10]. The reduction of the saturated vapor pressure shows a strong dependence on the concentration of the additive - the maximal effect was observed at the concentration of additive of $9.25 \mathrm{mg} / \mathrm{kg}$ (Table 3). This can be explained by the formation of associations of molecules in the surface layer when the additive concentration is greater than $9.25 \mathrm{mg} / \mathrm{kg}$, which increases the molar concentration of gasoline in the surface layer. 
Table 3: Dependence of saturated vapor pressure of the gasoline on the additive concentration.

\begin{tabular}{|c|c|}
\hline Concentration of additive, $\mathrm{mg} / \mathrm{kg}$ & Saturated vapor pressure, $\mathrm{kPa}$ \\
\hline 0 & 54 \\
\hline 4.25 & 52 \\
\hline 9.25 & 47 \\
\hline 18.50 & 52 \\
\hline 27.75 & 52 \\
\hline
\end{tabular}

Table 4 provides the data on the influence of the developed additive on the saturated vapor pressure of $n$-hexane and gasolines.

Table 4: Influence of the additive on the saturated vapor pressure (at the concentration of additive of $9.25 \mathrm{mg} / \mathrm{kg}$ ).

\begin{tabular}{|c|c|c|}
\hline \multirow[t]{2}{*}{ Product } & \multicolumn{2}{|c|}{ Saturated vapor pressure, $\mathrm{kPa}$} \\
\hline & Without additive & With additive \\
\hline n-hexane & 29.7 & 23.5 \\
\hline Gasoline, sample 1 & 51.0 & 43.0 \\
\hline 2 & 72.0 & 61.0 \\
\hline 3 & 98.0 & 72.0 \\
\hline
\end{tabular}

The effect of the additive on the surface tension of gasoline is characterized by the data presented in Table 5 .

Trough of the dependence of the surface tension on the concentration of the additive is observed at $9.25 \mathrm{mg} / \mathrm{kg}$ like that for the saturated vapor pressure. Reducing the surface tension increases the total droplet surface of the injected gasoline and, therefore, the rate of evaporation in the engine carburetion increases.

Table 5: Influence of the additive concentration in gasoline with research octane number (RON) 95 on the surface tension along the border with air at $20^{\circ} \mathrm{C}$.

\begin{tabular}{|c|c|}
\hline Concentration of additive, $\mathrm{mg} / \mathrm{kg}$ & Surface tension, $\mathrm{mN} / \mathrm{m}$ \\
\hline 0 & 25.47 \\
9.25 & 20.61 \\
18.5 & 21.89 \\
27.75 & 22.05 \\
\hline
\end{tabular}

It should be noted that lowering the surface tension is much more remarkable in the case of the low aromatic gasoline and this may attain $23.6 \%$ (according to results received by author) in comparison with $8.3 \%$ for the highly aromatic fuel as was shown in Table 5. Taking into account that the evaporation rate of 
fuel drops during injection is inversely proportional to the square of the surface tension, which had been established by the author, as a result of additive application it will increase by almost 1.2 times for the highly aromatic gasoline with RON 95 and by 1.7 times for the low aromatic one.

When the saturated vapor pressure is reduced the additive has very little effect on the initial boiling point of gasoline and no impact on the temperature of $10 \%$ distillation (Table 6), and thus does not lead to deterioration of cold start.

Table 6: Influence of the additive on the initial boiling point and the temperature of $10 \%$ distillation (additive concentration is $9.25 \mathrm{mg} / \mathrm{kg})$.

\begin{tabular}{|c|c|c|c|c|}
\hline \multirow{2}{*}{$\begin{array}{c}\text { RON of } \\
\text { gasoline }\end{array}$} & \multicolumn{2}{|c|}{ Initial boiling point, ${ }^{\circ} \mathrm{C}$} & \multicolumn{2}{c|}{$\begin{array}{c}\text { Temperature of } 10 \% \\
\text { distillation, }{ }^{\circ} \mathrm{C}\end{array}$} \\
\cline { 2 - 5 } & $\begin{array}{c}\text { Without } \\
\text { additive }\end{array}$ & $\begin{array}{c}\text { With } \\
\text { additive }\end{array}$ & $\begin{array}{c}\text { Without } \\
\text { additive }\end{array}$ & $\begin{array}{c}\text { With } \\
\text { additive }\end{array}$ \\
\hline 92 & 46 & 48 & 66 & 66 \\
95 & 40 & 41 & 70 & 70 \\
\hline
\end{tabular}

It is worth noting that a reduction in the saturated vapor pressure by introducing the additive makes it possible to increase the concentration of the environmentally friendly high-octane components of the gasoline - butanes. Reducing the saturated vapor pressure by $15-20 \%$ corresponds to the same decrease in evaporation losses (Table 7). At the additive concentration equal to $9.25 \mathrm{mg} / \mathrm{kg}$ the evaporation losses of heavy gasoline at $30^{\circ} \mathrm{C}$ reduce by $17.5 \%$, losses of light gasoline at $20^{\circ} \mathrm{C}$ - by $19 \%$, and losses of the isopentane-n-hexane mixture - by $30 \%$. The effect of loss reducing decreases when the concentration of the additive exceeds $9.25 \mathrm{mg} / \mathrm{kg}$.

Table 7: Reducing the evaporation losses, estimated by Budarov's method (Russian State Standart 6369-52), wt.\%.

\begin{tabular}{|c|c|c|c|}
\hline & & \multicolumn{2}{|c|}{ Losses from evaporation, wt.\% } \\
\cline { 3 - 4 } Gasoline & Temperature, ${ }^{\circ} \mathrm{C}$ & Without additive & With additive \\
\hline Sample $1^{*}$ & 30 & 4.0 & 3.3 \\
Sample 2** & 20 & 4.2 & 3.4 \\
Sample 3*** & 20 & 5.3 & 3.7 \\
\hline
\end{tabular}

* The saturated vapor pressure is $53.3 \mathrm{kPa}$, the intitial boiling point is $58^{\circ}$, the temperature of $10 \%$ distillation is $64^{\circ}$;

** The saturated vapor pressure is $83.7 \mathrm{kPa}$, the intitial boiling point is $41^{\circ}$, the temperature of $10 \%$ distillation is $52^{\circ}$;

***Isopentane-n-hexane mixture 1:1 (volume ratio)

During storage of the gasoline in opened conical flasks in a fume cupboard (temperature varied between $22-26^{\circ} \mathrm{C}$ ) for 5 hours the evaporation loss of the gasoline with the additive $(9.25 \mathrm{mg} / \mathrm{kg})$ was $10.2 \%$ lower than that without the additive (4.93 and 5.49 wt.\%, respectively), for 28 hours a decrease in the 
evaporation loss amounted to $17.6 \%$ (24.43 wt.\% for the gasoline without additive and 20.13 wt. $\%$ for the gasoline with additive). Thus, there is a very substantial reduction in the evaporation losses from the fuel during storage when the additive content therein is $9.25 \mathrm{mg} / \mathrm{kg}$ and at the present volume of gasoline consumption such reduction has both economic and ecological importance.

The combined effect of the additive on the saturated vapor pressure and surface tension provides valuable technical results - reducing gasoline loss from evaporation and improving mixture formation during gasoline injection into the engine.

The results of studies of the effect of the additive on the saturated vapor pressure, evaporation loss and surface tension of the gasoline are presented in fig. 1.

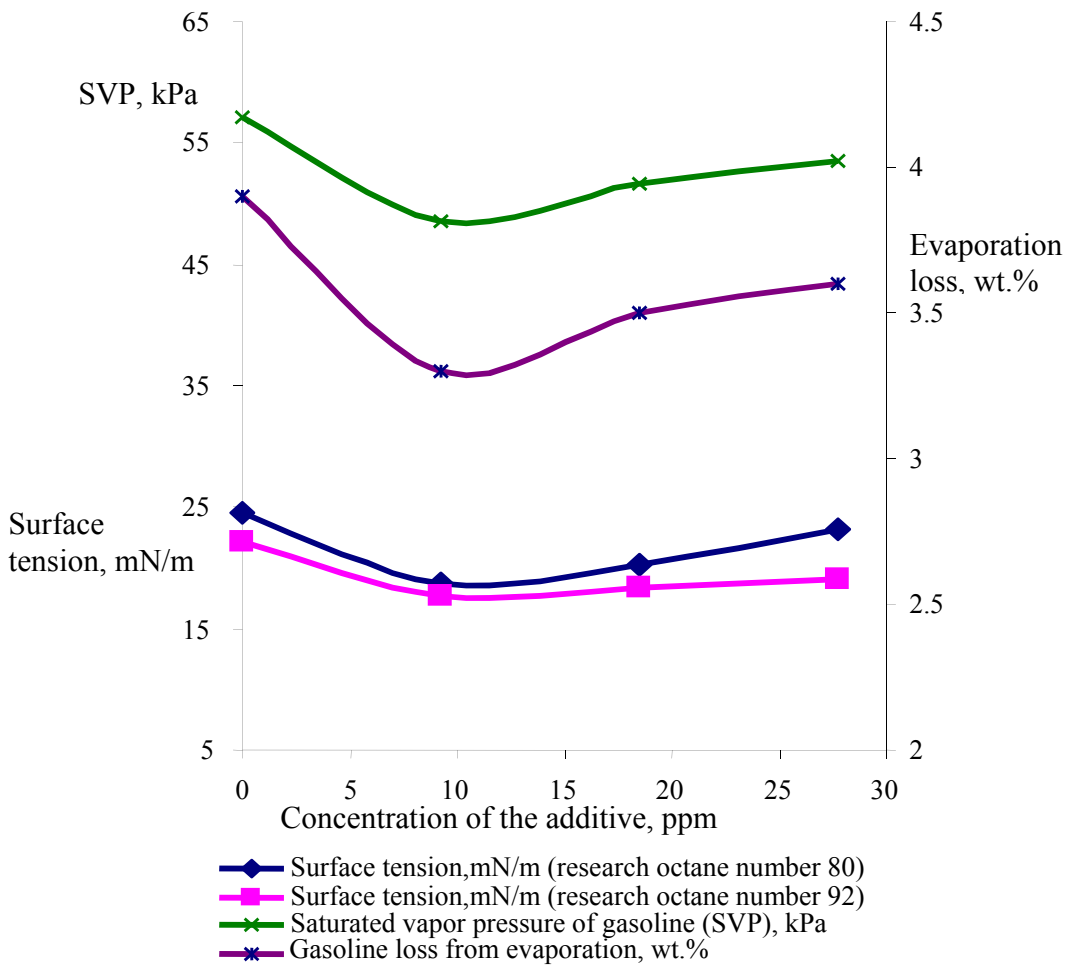

Figure 1: The influence of the additive concentration on the value of surface tension at the $15^{\circ} \mathrm{C}$, on the saturated vapor pressure of the gasoline and the gasoline loss from evaporation. 


\section{Conclusion}

The decisive contribution of benzene to the overall toxicity of gasoline vapor was theoretically proved which necessitates limiting its content in gasoline to the minimum possible. This requires a shift in priorities of the refining industry in the direction of an accelerated increase in isomerization capacity with an exclusion of the fractions boiling above $100^{\circ} \mathrm{C}$ from the raw material under reforming. A method to reduce gasoline loss to evaporation by the introduction of a trace amount of the surface-active fuel additive was developed. Usage of the additive significantly improves the efficiency of the gasoline currently in production, reduces the negative environmental impact caused by the loss of light hydrocarbons and also improves the performance characteristics of vehicles.

\section{Acknowledgement}

This research is funded by the Russian Scientific Fund (Research Project 15-1930001).

\section{References}

[1] Sharov. M., Levashov, A., Michailov, A., The Irkutsk Transportation Master Plan Solutions for public transport system development. WIT Transactions on Ecology and The Environment, 190, Volume 1, WIT Press: UK, pp. 651-660, 2014.

[2] Magaril, E., The solution to strategic problems in the oil refining industry as a factor for the sustainable development of automobile transport. WIT Transactions on Ecology and The Environment, 190, Volume 2, WIT Press: UK, pp. 821-832, 2014.

[3] Magaril, E. The influence of carbonization elimination on the environmental safety and efficiency of vehicle operation. International Journal of Sustainable Development and Planning, 8(4), pp. 1-15, 2013.

[4] Magaril, E., Improving the efficiency and environmental safety of gasoline engine operation. WIT Transactions on Built Environment, 130, WIT Press: UK, pp. 437-485, 2013.

[5] Magaril, E.R., Magaril, R.Z., Bamburov, V.G., Specific features of combustion in gasoline-driven internal combustion engines. Combustion, Explosion and Shock Waves, 50 (1), pp. 75-79, 2014.

[6] Worldwide Fuel Charter, 5th edition, 2013, http://www.acea.be/uploads/ publications/Worldwide_Fuel_Charter_5ed_2013.pdf

[7] Magaril, E.R. Influence of the quality of engine fuels on the operation and environmental characteristics of vehicles: monograph, [in Russian], KDU: Moscow, 2008.

[8] Magaril, E.R., Magaril R.Z. Motor fuels [in Russian], second edition, KDU: Moscow, 2010. 
[9] Magaril, E., Magaril, R. Motor fuels: the problem of energy efficiency and environmental safety: monograph, [in Russian], LAP Lambert Academic Publishing GmbH \& Co: Saarbrücken, Germany, 2012.

[10] Magaril, E., Improving car environmental and operational characteristics using a multifunctional fuel additive. WIT Transactions on Ecology and the Environment, 147, WIT Press: UK, pp. 373-384, 2011. 